\title{
Agglomeration Economies among Animal and Crop Producers in Nigeria: A Panacea for Diversification and Sustainable Economic Growth in South Eastern Nigeria
}

\author{
Omeje Emmanuel E \\ Department of Agricultural Economics \\ University of Nigeria, Nsukka, Nigeria \\ Email: ejiofor.omeje@unn.edu.ng \\ Tel: 08038090907 \\ Onah Ogochuchukwu G \\ Department of Agricultural Economics \\ University of Nigeria, Nsukka, Nigeria \\ Chiemela Peter $\mathbf{N}$ \\ Division of Animal and Dairy Science \\ Chungnam National University \\ Daejeon 34134, Republic of Kore \\ Agbo Nneka $\mathbf{H}$ \\ National Productivity Centre \\ Enugu State Office
}

Received: December 10, 2018

Accepted: December 15, 2018

Online Published: December 31, 2018

\begin{abstract}
This paper investigates agglomeration economies among Farmers in cluster areas of South Eastern Nigeria as a tool for economic emancipation with a special interest in diversification and growth. It also identified other vital roles agglomeration plays in developing economies like Nigeria. These are not only as tools for poverty alleviation and diversification of sources of livelihood among farmers but also tools for employment generation and sustainable economic growth. This paper was motivated by the quest to provide urgent policy recommendations for a sustainable approach to agricultural development in South Eastern Nigeria. The specific objectives of the study were to: (i) describe the socioeconomic characteristics of the respondents; (ii) ascertain the perception of the farmers on diversification and other benefits from agglomeration locations in the region, and (iii) ascertain the challenges militating against diversification and economic growth as benefits from agglomeration clusters. Descriptive survey research design and structured questionnaire were adopted for this study. Pearson's product moment correlation method and split half technique were adopted to determine the internal consistency of the instrument on 150 questionnaires retrieved and reliability coefficient of 0.91 was obtained. Objective (i) and (ii) were realized using descriptive statistics and charts while Objective (iii) was realized using weighted mean, standard deviation and rankings. Majority of the farmers were within the active age of 40-49 years. Basic education (69.3\%) was also pronounced and most farmers operate either medium or large-scale farming. Farmers were of the views that they had benefited immensely from agglomeration economies especially in areas of transportation, diversification, access to information and innovation as well as access to credit. Fear of risks and uncertainties, dependency on rain-fed farming, and limited access to long-term credit ranked highest among the critical challenges limiting them from diversification and economic growth potentials in agglomeration.
\end{abstract}

Keywords: Agglomeration Economies, Economic Growth, Diversification and South Eastern Nigeria 


\section{Introduction}

The primary ideology of agglomeration economies among farmers is that production and processing are facilitated when there is an effective cluster of linked economic activities. The concept of agglomeration economies is akin to the explanations and ideas of economies of scale and network effects respectively. According to Edward (2010), agglomeration economies are the benefits that come when firms and people locate near one another together in a place or industrial clusters. Edward was of the view that all these benefits ultimately come from transport cost savings and that transportation costs could be interpreted broadly to include the difficulties in exchanging goods, people, services, and ideas. While we agree with Edward that transportation benefit is central, we further conceptualized the view that agglomeration economies is also capable of influencing diversification and improving economic growth among others. This is true because even the simplest activity in the farm requires a network of supporting linkages, services and markets that individual firms or farms cannot organize. Those who doubt the awesome potentials of agglomeration economies should visit Dongguan, a city halfway between Guangzhou and Shenzhen in Southeast China.

The World Development Report (2009) offered a useful classification of the different types of scale economies. According to the report, there are three broad categories: internal economies, localization economies and urbanization economies. The internal economies arise from larger plant sizes (better deals from suppliers, division of labour); localization economies arise from the clustering of firms in the same industry or in the same space (which increases the supply of information and the pool of specialized labour); and urbanization economies which arise from having a large number of industries in the same place. Hence, internal economies are firm specific (and are greater in heavy industries where plant sizes are larger). Localization benefits accrue within a given industry and urbanization benefits are typically realized across industries.

According to Alan, Gaiv, Vijaya, and Ivan (2015), agglomeration benefits have been sought in industries and spatial areas through a variety of modalities, including industrial zones, Special Economic Zones and other similar institutional arrangements with varying degrees of success of which China probably has the best record. However, replication of the Chinese model in Sub-Saharan Africa and other developing countries like Nigeria has been very challenging. Farole (2011) provides a very useful overview of how special agglomeration economic zones or clusters have fared in Sub-Saharan Africa. Alan, et al, (2015) also noted that the intellectual clarity of the agglomeration approach may be overestimated if its implementation challenges are ignored during policy formulation. The authors added that agglomeration projects and local investment clusters can have a large effect on land values, raising issues of ownership, massive by-waste, control, and allocation. This is an important issue here since land tenure has always been a critical challenge to Nigerian agriculture. This same land reform issues is a major critique to the location theory for agricultural sector developed by Von Thünen which recommended the optimal use of land for an isolated city (Lang 2014). Other major observable challenges to economies of agglomeration may include: Strong environmental pressures leading to land degradation and pollution; high land prices; bottlenecks in public goods such as overburdened infrastructure; corruption and exploitation; and unfavorable competitive pressures.

Many theories revolve round this economies of agglomeration.?

While some economic theories suggest that agglomeration might ease coordination failures in particular sectors or geographic locations, Weber (1909) exploited a neoclassical location approach for industrial companies to find the optimal production location based mainly on regional endowments and transportation costs. These regional, cluster or spaceless endowments may be explained to include: a great local market; large supply of labour and thus the increased chance of supply and demand for labour and lower search costs; the accumulation of knowledge and human capital which lead to knowledge, skills, ideas and information spillovers between firms and individuals; the basis for distribution and growth of diversification; the quicker diffusion and adoption of innovation; and the quicker access to credit facilities among farmers as well as between farmers and formal credit institutions. Also related to this conceptualization is the general equilibrium theory of spaceless economics which would then be a special case in which transport costs are zero and therefore disregarded and all inputs and outputs are perfectly mobile (Lang 2014). The mobility in this context means that needed resource inputs are not only available but also accessible and that market for output is also not a problem. This is true among farmers in cluster areas because it is easier for farm and off farm activities to boom under this arrangement. Take for instance, rice farmers produce at maximum capacity because rice millers are on the standby, enterprises engaged in de-stoning of rice are making progress because they have enough raw material at nearly zero transport cost, buyers from all parts of the country head to the rice market in the same cluster area to make purchases and this results to a boom in the transport sector. In all these, direct and indirect services and labour are created, agricultural jobs increased and its demand and supply stabilised.

Many research outputs on the economies of agglomeration suggest that benefits such as diversification and economic growth as well as its demerits vary with location (Ellison and Glaeser, 1999). Rigby and Essletzbichler 
(2002); Rosenthal and Strange (2001, 2003) and Baldwin, Brown, and Rigby (2008, 2010), all keyed on seeking evidence of the relative benefits of labour pooling, buyer/supplier networks, and knowledge spill-over across different industries and regions. This is a major research gap in South Eastern Nigeria. To fill this gap which will assist development stakeholders in making relevant policies, this paper was guided by three relevant research questions which include: what is the socioeconomic characteristics of farmers involved in agglomeration economies or clusters? What are their views regarding benefits of agglomeration to diversification among others? And in their opinion, what are the major challenges facing the practice and its benefits to diversification and economic growth in the area?

The broad objective of the study was therefore, to ascertain the contribution of economies of agglomeration to diversification and economic growth among farmers in southeastern Nigeria. The specific objectives of the study were to: (i) describe the socioeconomic characteristics of the respondents; (ii) ascertain the perception of the farmers on diversification and other benefits from agglomeration locations in the state; and (iii) ascertain the challenges militating against economic diversification and growth arising from agglomeration or clusters.

\section{Methodology}

Descriptive survey research design was adopted for this study. Structured questionnaire was used for collecting data from respondents. The study area was South Eastern Nigeria including Abia, Anambra, Ebonyi, Enugu and Imo States. The sample for the study was 150. A purposive random sampling technique was used to select 150 farmers that were involved in agglomeration activities or linked cluster areas. Aba in Abia State, Abakiliki in Ebonyi State and Uzouwani in Enugu State were purposively selected due to their dominance in cluster-related agglomeration economies. Fifty respondents were randomly selected from each of the 3 states. Pearson's product moment correlation method and split half technique were adopted to determine the internal consistency of the instrument on 150 questionnaires retrieved. A reliability coefficient of 0.91 was obtained.

Objective (i) and (ii) were realized using descriptive statistics such as frequency, mean, and charts while Objective (iii) was realized using weighted mean, standard deviation and ranks. Decision on the level of agreement by the respondents with each elements of the critical constraints to agglomeration was observed as: (i) the element of each critical constraint that had the highest weighted mean was ranked first and considered the element with highest agreement by the respondents as challenging to their engagement in agglomeration; (ii) any element with a standard deviation below 1.96 indicates that the respondents were not too far from the mean and from the opinion of one another, while any elements with a standard deviation above 1.96 indicated that the respondents were far from the mean and from the opinion of one another.

\section{Results and Discussion}

\subsection{Socioeconomics of the Farmers Involved in Agglomeration Activities}

The result in figure 1 shows that the responses of respondents on age, marital status, literacy level, income level, farm size and types of farming. Majority of the farmers were within the active age of 40-49 years which constituted the highest percentage of $34 \%$ among the group. The respondents between 60 years and above had the lowest percentage of $9.35 \%$. This result follows the normal distribution curve for agricultural employment where active young people participate more in the farming activities such as in clusters.
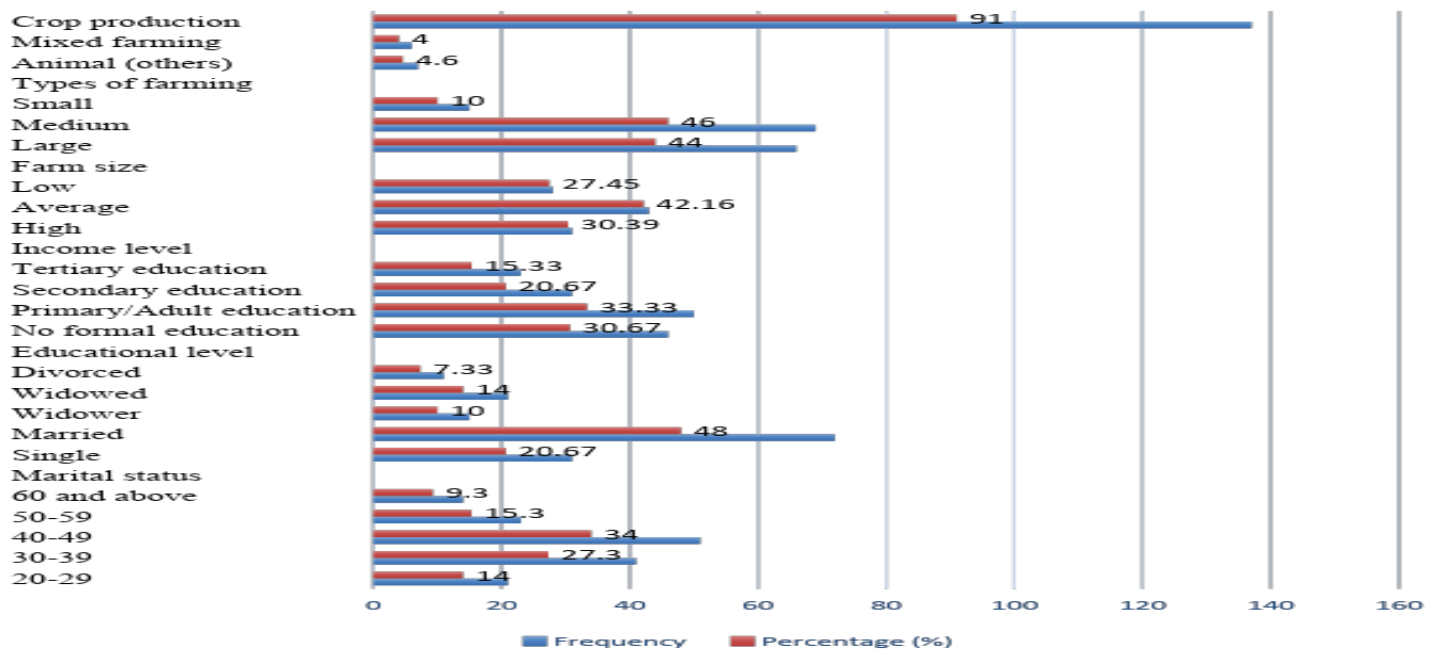

Figure 1: Distribution of respondent according to socio-economic characteristics $\mathrm{N}=150$. Source: Field Survey, 2018 
It entails that the younger population maybe engaged in schooling while the elderly people are retiring from farming activities. In terms of marital status, $48 \%$ were married while $20.67 \%$ of the respondents were single. However, the lowest percentage among them was divorcee with $7.33 \%$. In terms of literacy level, high percentage of the respondents (69.3\%) had formal education, $30.7 \%$ had no formal education. The farm size distribution of the respondents shows that $44 \%$ and $46 \%$ of the farmers had large and medium size farms respectively while $10 \%$ had small farm sizes. This result suggests that many of the farmers are actually benefiting from the agglomeration hence fewer small scale farmers. With regards to the types of farming, the result indicates that crop production was most practiced in the area with $91 \%$ of the respondents involved in the production. This implies that crop production provides a greater source of livelihood as engaged by many people in the cluster regions.

\subsection{Diversification and Other Benefits of Agglomeration Economies}

The results presented in table 2 showed that majority of the respondents (78.7\%) were in agreement that economic growth was one of the major benefits from their agglomeration activities. It showed that easier transportation (76.6\%), economic diversification (73.3\%) and adoption of innovation (73.3\%) were also part of the major benefits of agglomeration within their clusters. Other benefits from their activities include: quick and easier diffusion of idea/information (50\%), quicker access to credit (90\%) and access to viable and efficient market $(75.3 \%)$.

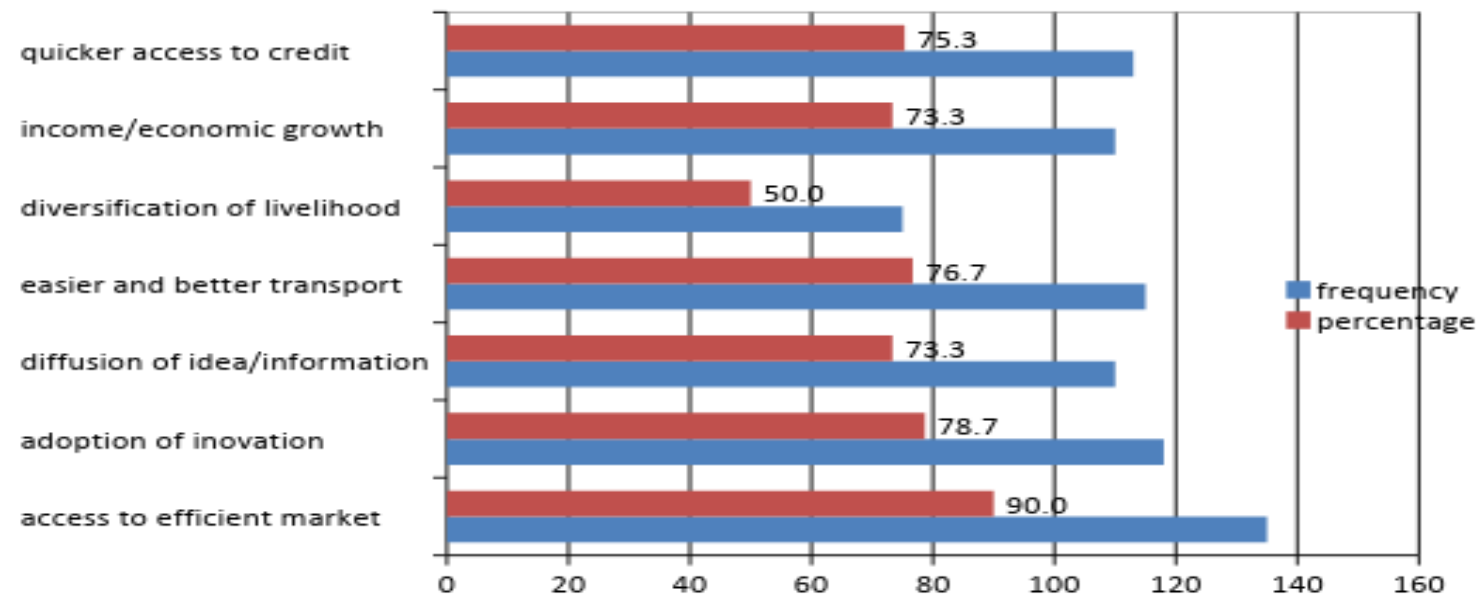

Figure 2: Frequency distribution showing the agreement of respondents on benefits of agglomeration economies.

$$
\mathrm{N}=150
$$

Source: Field Survey, 2017

3.3 Critical Challenges to Diversification and Economic Growth as Benefits of Agglomeration economies

The result in table 3 below showed that the mean values of the respondents on the elements of challenges to diversification and economic growth as benefits of agglomeration economies ranged from 2.41 to 3.92. This shows that each element in the table has significant influence as constraint to diversification and economic growth as benefits of agglomeration economies. The critical elements of the constraints as shown in the table are: Fear of risks and uncertainty (3.92); Poor supply of electricity (3.41); and Poor access to long term credit (3.37) which was ranked as $1^{\text {st }}, 2^{\text {nd }}$ and $3^{\text {rd }}$ respectively.

Table 1: Mean Rating and Rank Order to the Respondents' Agreement on challenges to diversification and economic growth as benefits of agglomeration economies

\begin{tabular}{|l|l|c|l|l|}
\hline S/N & diversification and economic growth as benefits of agglomeration economies & $\bar{X}$ & SD & Rank \\
\hline 1 & Corruption/exploitation by government agents & 2.71 & 0.81 & $7^{\text {th }}$ \\
\hline 2 & Poor infrastructure and Poor supply of electricity & 2.83 & 0.81 & $6^{\text {th }}$ \\
\hline 3 & insecurity & 2.41 & 0.53 & $8^{\text {th }}$ \\
\hline 4 & Fear of risks and uncertainty & 3.92 & 0.64 & $1^{\text {st }}$ \\
\hline 5 & dependency on rain-fed farming & 3.41 & 0.67 & $2^{\text {nd }}$ \\
\hline 6 & Land tenure/pressure & 3.11 & 0.76 & $4^{\text {th }}$ \\
\hline 7 & Poor access to long term credit & 3.37 & 0.90 & $3^{\text {rd }}$ \\
\hline 8 & Unfavourable competitions & 2.92 & 0.74 & $5^{\text {th }}$ \\
\hline
\end{tabular}

Source: Field survey, 2018. 
The standard deviation of the ranked items ranged from 0.53 to 0.90 indicating that responses were very close and therefore, shared similar opinions.

\section{Conclusion}

This study showed the importance of agglomeration economies among farmers in poverty alleviation, job creation and economic growth of the region. It also explained the socioeconomic characteristics of the farmers and the perceptions of the farmers on their benefits from such agglomeration activities. However, the study highlighted some of challenges to diversification and economic growth as benefits of agglomeration economies. This paper therefore suggests that government and relevant stakeholders should find solutions to the stated problems to enable them harness these potentials.

\section{References}

Edward, L. G. (2010). Agglomeration Economics. National Bureau of Economic Research. The University of Chicago Press, http://www.nber.org/chapters/c7977

Alan, G., Gaiv, T. Vijaya, R. and Ivan, R. (2015). "When Agglomeration Theory Meets Development Reality: Preliminary Lessons from Twenty World Bank Private Sector Projects." CGD Policy Paper 054. Washington DC: Centre for Global Development. http://www.cgdev.org/publication/when-agglomerationtheory-meets-development-reality-preliminary-lessons-twenty-world

Lang, G. (2014). Macro attractiveness and micro decision in the mutual fund industry: an empirical analysis. Hardcover, xii, 178, page 22. http://www.springer.com/978-3-642-39723-3

World Bank, (2009). World Development Report 2009: Reshaping Economic Geography. Washington DC: The World Bank Group.

Farole, T. (2011). Special Economic Zones in Africa: Comparing Performance and Learning from Global Experience. World Bank: Directions in Development.

Ellison, G., and E. Glaeser. 1999. "The Geographic Concentration of Industry: Does Natural

Advantage Explain Agglomeration?" The American Economic Review. Vol. 89. No. 2. p.

311-316.

Rigby, D.L., and J. Essletzbichler. 2002. "Agglomeration economies and productivity differences in U.S. cities." Journal of Economic Geography. Vol. 2. No. 4. p. 407-432.

Rosenthal, S.S., and W.C. Strange. 2001. "The Determinants of Agglomeration." Journal of

Urban Economics. Vol. 50. No. 2. p. 191-229.

Rosenthal, S., and W. Strange. 2003. "Geography, Industrial Organization, and Agglomeration." The Review of Economics and Statistics. Vol. 85. No. 2. p. 377-393.

Baldwin, J., D. Beckstead, W.M. Brown, and D.L. Rigby. 2008. "Agglomeration and the

Geography of Localization Economies in Canada." Regional Studies. Vol. 42. No. 1. p. 117-132.

Baldwin, J.R., W.M. Brown, and D.L. Rigby. 2010. "Agglomeration Economies: Microdata Panel Estimates from Canadian Manufacturing." Journal of Regional Science. Vol. 50. No. 5. p. 915-934.

\section{Copyrights}

Copyright for this article is retained by the author(s), with first publication rights granted to the journal. This is an open-access article distributed under the terms and conditions of the Creative Commons Attribution license (http://creativecommons.org/licenses/by/4.0/). 